\title{
Towards an understanding of contextual features that influence the linguistic formality of British Sign Language users
}

\author{
Luke A. Rudge(D)
}

Correspondence:

luke.rudge@live.uwe.ac.uk

Bristol Centre for Linguistics,

University of the West of England,

Frenchay Campus, Bristol BS16 1QY, UK

\begin{abstract}
This paper seeks to understand linguistic formality through the identification and measurement of contextual features. Using an adapted sociometric methodology to combine systemic functional linguistics and sign linguistics, a survey identifies the elements of context that have an effect upon the level of linguistic formality employed by British Sign Language users. The responses of 51 participants are analysed in order to ascertain (i) the level of linguistic formality that would be employed in certain communicative scenarios, and (ii) the contextual features of these scenarios that have an influence on linguistic formality. The results obtained from this study posit that there is an overall agreement shared between British Sign Language users when choosing levels of linguistic formality based on broad contextual description alone. The people involved in the communication and their interpersonal relationships tend to be the biggest influence on the level of formality employed, whereas the topic of the interaction appears to show no significant influence upon linguistic formality on its own. This work contributes further evidence to the importance of studying language within communicative contexts and the importance of formality as an influential factor in linguistic production. It is hoped that this will encourage future studies to derive linguistic data of British Sign Language users, or indeed users of other sign languages, to corroborate these findings.
\end{abstract}

Keywords: Context, British Sign Language, Formality, Systemic Functional Linguistics

\section{Main body Introduction}

Formality is referred to throughout many pieces of literature, both in the linguistic and contextual senses (e.g. Wish and Kaplan 1977; Labov 1984; Eckhert and Rickford 2001; Heylighen and Dewaele 2002). Although studies that focus specifically on the nature of formality are not as extensive, it is generally agreed that the formality of a situation will have some effect on the language used. Such variation ranges from a subtle shift in vocabulary or syntax (Levin and Garrett 1990) to the modification of almost every element within an utterance (Strauss and Eun 2005). In the domain of sign linguistics, including the many sub-disciplines found therein, the links between contextual and linguistic formality are yet to be researched in as much detail as that which is found in the study of spoken and written languages. Thus, several gaps in current knowledge exist that would benefit from further research.

(c) 2015 Rudge. Open Access This article is distributed under the terms of the Creative Commons Attribution 4.0 International License (http://creativecommons.org/licenses/by/4.0/), which permits unrestricted use, distribution, and reproduction in any medium, provided you give appropriate credit to the original author(s) and the source, provide a link to the Creative Commons license, and indicate if changes were made. 
This paper presents an investigation into how linguistic and contextual formality interact with one another from the point of view of British Sign Language (BSL) users. The goal of this research is to identify elements of context that have a significant effect on the language employed in particular communicative scenarios, with a further aim of identifying significant patterns of contextual elements that contribute towards formality or informality in language. Firstly, current research in this area of study, albeit intermittent, is reviewed, together with a brief synopsis of systemic functional linguistics (SFL) and its theoretical standpoint on the relationship between language and context. A study carried out with a random sample of members of the British Deaf community is then detailed, followed by a review of the results obtained. The discussion analyses salient contextual patterns and correlations regarding interpretations of formality, with suggestions for future study and methodological improvements, whilst bearing in mind the particular idiosyncrasies of research within Deaf communities. ${ }^{1}$

\section{Literature review}

Studies on formality are by no means rare, particularly for spoken and written languages. Early work, such as that of Joos (1961), presents five possible styles of spoken English ranked in order of their linguistic formality - from 'intimate' (most informal) to 'frozen' (most formal) - based upon certain contextual and linguistic characteristics. While studies would go on to evaluate and support these proposed styles (e.g., Broderick 1978), later studies have since superseded the notion of discrete levels of formality, demonstrating that formality is better schematised on a continuum ranging from 'informal' to 'formal' (Arndt and Janney 1987; Biber 1995; Rooy et al. 2010; Li et al. 2013). In these later studies, language is deemed more formal or more informal according to linguistic aspects, such as the frequency of deictic words (Heylighen and Dewaele 2002), and cognitive aspects including the amount of attention paid to speech (Labov 1984). A range of qualitative and quantitative methods have thereby been employed in research on formality.

Concerning the concept of formality in visual-spatial languages, most works are centred on the use of American Sign Language (ASL; Zimmer 1989; Metzger 1993; Quinto-Pozos and Reynolds 2012), observing linguistic features such as discourse strategies and lexical choice. For BSL, however, there are far fewer studies available. Perhaps the earliest work to approach this area is Deuchar (1978) who observes linguistic variation in BSL and classifies this situation as diglossic. She proposes that two varieties of BSL exist: one that is more visually motivated, and another that blends English and BSL closely together. The former is found in situations of lower prestige (e.g., communicating with friends) and the latter in high prestige interactions (e.g., church services), thus a diglossic situation appears prominent. However, Lee (1982) calls this diglossia into question, stating that the differences identified by Deuchar (1978) and other researchers do not match the principles of diglossia as established by Ferguson (1959). Lee (1982) reformulates this observed variation in sign languages, quoting Joos' (1961) five styles, thereby introducing the possibility of a range of linguistic varieties rather than a simple dichotomy. Following Joos' classifications, these varieties are dependent upon multiple contextual and linguistic factors, including interpersonal distance between communicators and their shared background knowledge. 
Later, Deuchar (1984) reviewed the position of diglossia in BSL alongside further models of variation, including pidgins, creolisation, and a continuum of styles between BSL and 'Signed English:' "English represented as accurately as possible on the hands" (p.148). While each model is defended to an extent, Deuchar finalises her position in defining the situational variation found in BSL as "a complex of overlapping varieties" (ibid.) comprising BSL, Signed English, and pidgin varieties. She also notes that social and contextual variables, including formality, have influence on the linguistic style that BSL users adopt. Yet, unlike the model of diglossia proposed by Deuchar (1978), these latter variables are not accounted for in the model of overlapping varieties. Deuchar (1984) therefore comments that "more research is needed to relate (the variants of BSL) to their social context and to determine the relative importance of social factors such as formality/informality of setting" (p.149). In spite of this statement, however, any work regarding formality in BSL remained infrequent until around the turn of the millennium.

The most comprehensive work of BSL linguistics to date is Sutton-Spence and Woll's (1999) introductory textbook. ${ }^{2}$ Within their work, the authors describe what is observed in informal BSL. For example, informal signing incorporates a larger signing space (i.e., the space in front of the signers' body), greater use of non-manual features (i.e., facial gestures and expressions), and the production of two-handed signs using only one hand. Although it is not explicitly stated, it is assumed that the 'opposites' of the abovementioned features would thereby indicate a formal linguistic style, with Napier (2003) providing instances of where this language may appear: "academic lectures, business meetings, banquets, and church" (p.117). However, the features described are generally phonological in nature, and there is little further discussion on this variation. Furthermore, aside from Napier's abovementioned identification of domains, no further information is provided to indicate what is deemed as an 'informal' or 'formal' communicative situation, or how language varies at, for example, morphological or syntactic levels.

To contribute to this domain further, Stone (2011) examines linguistic variation in BSL at the level of discourse. With regard to formality, Stone similarly employs Joos' (1961) five styles in an experiment, asking two BSL users to identify the level of formality of two instances of discourse, based upon language content and production. The two participants broadly agree on the level of formality attributed to both productions, and jointly identify traits that are deemed formal and informal, such as whether the signer is standing up or sitting down, and the number of regional signs employed (see Stamp et al. 2015). Stone's (2011) findings both reinforce and add to what is provided by Sutton-Spence and Woll (1999), but caution must be taken when considering the recorded formality scores. Both participants in the study had a close interpersonal connection to the signer producing the stimulus discourse, and interpersonal proximity can affect the production and interpretation of language (see Berger and Bradac 1982).

When comparing the breadth of research carried out with spoken and written languages with that of sign languages, it is clear that studies in the latter are still very much in their infancy. Indeed, Stone (2011) mentions that "there is nothing else in the published domain on specific register features of BSL" (p.124), and it can be argued from the current literature review that this statement remains true today, especially with reference to formality. Nevertheless, research in sign linguistics is expanding at an increasing rate (Arik 2014) with much still to discover, 
notably that of the interaction of context and language. Systemic functional linguistics (SFL; Halliday 1978; Halliday and Matthiessen 2013) boasts numerous frameworks and methods linking context with language (Butler 2003). Whereas SFL has been applied comprehensively to a variety of spoken and written languages (Eggins 2004; Caffarel 2006; Lavid et al. 2010), very few studies in this domain have analysed languages in the visual-spatial modality, with perhaps Johnston (1996) as the exception. To increase the understanding of BSL from a functional perspective, the present study employs systemic functional theory to an investigation of BSL in order to identify the associations between communicative contexts and language use. While it is beyond the scope of this paper to discuss the benefits and challenges of applying systemic functional theory to sign languages, it is nonetheless necessary to identify and elaborate upon the notion of 'context,' and the associations between language use and communicative environments.

Systemic functional theory models human language as a stratified system (Halliday and Webster 2009), from the smallest components of the linguistic system through to more abstract notions such as 'genre' and 'ideology' (see Martin 2014). In this model of language, context is viewed as the overarching layer that encompasses the linguistic system, split into the three parameters of field, mode and tenor (Halliday and Hasan 1989; Halliday and Matthiessen 2013). While definitions of this trio vary between systemic functionalists, broad descriptions can generally be arrived at: field represents the experiential domain being expressed through the communication (i.e., the topic), mode signifies the manner in which the communication is performed, and tenor denotes the interpersonal relationships of those in the communicative context. These three contextual parameters have specific links to features found at the semantic and lexicogrammatical strata situated in the linguistic system, as attested to in most systemic functional literature (e.g. Figure 1-6 of Halliday and Matthiessen 2013).

A more thorough interrogation of 'context' from the systemic functional perspective quickly demonstrates that the aforementioned definitions for field, mode and tenor are not detailed enough to account for the numerous potential features found in a communicative environment. However, three works in particular - Leckie-Tarry (1995), Eggins (2004) and Halliday and Matthiessen (2013) - provide in-depth definitions for field, mode and tenor, each consisting of numerous quantifiable features. These three works maintain a degree of variation, approaching context with various levels of cognitive, social, and semantic predilection. When accumulated, nearly thirty features and their definitions are specified in these three works, some of which are duplicated and others that are unique to the theorists' interpretation. For instance, Eggins (2004) and Leckie-Tarry (1995) both identify 'feedback' (i.e., the time taken for a response to be given to an initial communication, if such a response occurs) as a feature of mode. However, Halliday and Matthiessen (2013) identify 'orientation' (i.e., whether the communication is ideational or interpersonal in its intent) as another feature of mode, yet neither Eggins (2004) nor Leckie-Tarry (1995) mention this. It is also noted by Van Dijk (2008) that many of these contextual features do not identify elements of context alone: some call on what is found in the text, rather than focussing solely on context. For example, Eggins (2004) identifies that field is related to the number of technical terms employed in communication, thereby focussing on linguistic features. 
This study works with the features identified in the three aforementioned works. However, the accumulation of these contextual features includes the merging of duplicates, and considers only those features that describe contextual elements rather than textual elements. As a consequence, the number of overall features reduces significantly. In the case of this study, seven features are established, identified in Table 1 below. These have been separated into their respective categories of field, mode and tenor, but it must be remembered that "the three contextual parameters (...) are not just three completely separate ingredients of social situations" (Hasan, 1999, p.272). In other words, despite their categorisation, there may be 'cross-category influence' (i.e., certain values of one features may augment or limit the choices in others; see Leckie-Tarry 1995 and Hasan 2014). In addition, Berry (2013) notes that features of tenor "seem to be more malleable" (p.376) than those found in field or mode. For instance, "it is possible for one of the interactants to attempt to decrease the social distance by using language more associated with a lesser social distance" (ibid.). Therefore, as the tenor can be controlled by the participants more so than other contextual parameters, it would be pertinent to bear this category of context in mind, and how this 'malleability' is reflected in the results of this study.

The connection between context and language as advocated in SFL has been and continues to be debated (Butler 2003), although most contemporary works claim a circular influence between context and language. Hasan (1999) explains this dialogic perspective thusly:

If in speaking, the speaker's perception of context activates her choice of meanings, then also the meanings meant in speaking construe contexts; and the same relation of activation and construal holds, mutatis mutandis, between meaning and lexicogrammar (p.223).

Thus, the communicative context will influence the language employed while the language will influence aspects of the context, through the activation of lower levels during linguistic production and the construal of higher levels during linguistic reception (Lukin et al. 2011). There are similar notions hypothesised with regards to influence, realisation, and metaredundancy (see Matthiessen et al. 2010), but what is vital to establish

Table 1 The seven contextual features measured in this study

\begin{tabular}{|c|c|c|c|}
\hline & Feature & Definition & Theorist(s) \\
\hline \multirow[t]{2}{*}{ Field } & $\begin{array}{l}\text { Socio-semiotic } \\
\text { activity }\end{array}$ & The action(s) accompanying the communication & Halliday and Matthiessen (2013) \\
\hline & Topic & The matter dealt with in the communication & Halliday and Matthiessen (2013) \\
\hline \multirow[t]{2}{*}{ Mode } & Turn & The structure of the text (e.g. monologic vs.dialogic) & Halliday and Matthiessen (2013) \\
\hline & Preparedness & $\begin{array}{l}\text { Whether a text is produced spontaneously or } \\
\text { has been planned prior to the interaction }\end{array}$ & Leckie-Tarry (1995) \\
\hline \multirow[t]{3}{*}{ Tenor } & Roles & The social functions played by the interlocutors & $\begin{array}{l}\text { Halliday and Matthiessen (2013); } \\
\text { Leckie-Tarry (1995) }\end{array}$ \\
\hline & Power & $\begin{array}{l}\text { The perceived distributions of authority between } \\
\text { the roles }\end{array}$ & $\begin{array}{l}\text { Halliday and Matthiessen (2013); } \\
\text { Eggins (2004) }\end{array}$ \\
\hline & Familiarity & How well-known the participants are to one another & $\begin{array}{l}\text { Halliday and Matthiessen (2013); } \\
\text { Eggins (2004) }\end{array}$ \\
\hline
\end{tabular}


here is the bidirectional interaction that occurs between the contextual and the linguistic strata.

This brief summary of context as understood from the systemic functional perspective reinforces the importance of incorporating context into the study of language, yet it only scratches the surface. The importance of studying language in context was established from the early proposals of Malinowski (1923) and reinforced by contemporary theorists such as Lemke (1988) who stated that "the actual occurrence-meaning, use-meaning or text meaning of a word or phrase depends entirely on its contextualization" (p.165). More recent works including Bowcher $(2013,2014)$ and Hasan (2014) attempt to schematise the complex relationships and representations of context via system networks, drawing parallels between the paradigmatic organisations of language and context. In short, the understanding of context from the systemic functional perspective is now far more advanced than it has ever been, but there is still much work to be done before 'context' may be fully defined.

This literature review has, amongst other things, demonstrated that studies into formality in sign languages generally focus on the language employed, paying relatively little attention to context. Given that SFL views context and language as "two sides of the same coin" (Hasan, 1993, p.86), the following study takes a different approach by prioritising contextual aspects over linguistic aspects. By using the features identified in Table 1 above, the influence of the communicative contexts on language production can be investigated, particularly when considering formality. This study therefore aims to shed light on the following questions: to what extent do Deaf BSL users agree with their interpretation of formality using contextual information, and what are the contextual features that contribute to the development of more formal or more informal contexts?

\section{Methodology}

This study adapts a sociological approach by Wish and Kaplan (1977). In their work, the authors attempt to ascertain how interpersonal relationships between individuals are affected by differing contexts. A series of brief "communication episodes" (p.236; referred to hereafter as 'scenarios') were designed and distributed to each research participant. The scenarios were accompanied by 14 bipolar scales of interpersonal features, such as friendly vs. hostile and engrossed vs. uninvolved, on which participants identified the level that they believed the scenario represented. The results obtained were "highly significant" (p.245), identifying five dimensions that communicators value as important in interpersonal relationships, one of which is formality. Wish and Kaplan's study also corroborated findings of similar behavioural studies, suggesting that this methodology can be reliably adapted into further work.

In order to understand how BSL users adapt their linguistic formality in different scenarios, a survey based on Wish and Kaplan (1977) was created, bearing similarity to a subjective reaction test (see Labov 1972). This survey employed twelve brief scenario descriptions as stimuli. However, rather than focussing on interpersonal relations between communicators, the aim was to understand how formal or informal a BSL users' language would be in these scenarios, and the features found therein that are salient in deciding the level of linguistic formality. 
Google Forms was chosen as the survey platform due to its ease of access by participants, ease of distribution, and its ability to embed videos: a necessary requirement to enable access to the survey in the participants' preferred language (i.e. BSL). As opinions were sought from a wide population, the survey was distributed via a social networking platform towards two groups that serve the British Deaf community, each containing roughly 6000 and 3000 members respectively at the time of distribution.

A Deaf presenter, proficient in both BSL and English, was asked to record the videos used in the survey. With a native understanding of BSL, the presenter was able to take into account that the survey was directed towards a UK-wide audience. Therefore, he adapted his signs into those that would be more easily understood by such an audience, rather than using the region-specific variations in signs (see Stamp et al. 2015). Additionally, he was able to ensure as close a match as possible between the written English provided on the autocue and the resulting BSL. This assured that what is written in this study in English matches that which was signed towards the participants in BSL.

Prior to these scenarios being displayed, two brief video clips were played giving information in BSL about the overall survey and what was to be asked of the participants in each question. The videos also informed participants that all responses would be anonymous, that participation was optional, and that participants could leave the survey at any time and for any reason.

The twelve scenarios used in this study are shown in Table 2. Each scenario was designed to be brief, yet to contain four specific elements: the topic of communication, the type of communication (e.g. a presentation, a chat, a debate, etc.), the place in which the communication occurs, and the people involved in the communication. This can be exemplified via scenario A: 'Discussing the General Election with friends in a café.' Here, it is possible to identify the topic (General Election), the type of communication (discussion), the place (a café) and the people involved (friends). These four factors were chosen as they relate to the seven contextual features identified in Table 1, thereby allowing for responses to be analysed with regards to these features. Berger and Bradac (1982) identify that in studies involving specific social situations, there are innumerate potential configurations, and as a consequence, such studies run the risk of

Table 2 The twelve scenarios used in the survey

\begin{tabular}{ll}
\hline & Scenario description \\
\hline B & Discussing the General Election with friends in a café \\
C & Negotiating a pay rise with your boss in their office \\
D & Ordering food from a waiter in a restaurant \\
E & Giving a presentation at work to your colleagues about how to book an interpreter \\
F & Telling your boss in the staff room about a restaurant you like \\
$\mathrm{G}$ & Instructing a new colleague at work on how to book an interpreter \\
$\mathrm{H}$ & Telling a story to your housemates at home about how you got a pay rise \\
$\mathrm{I}$ & Recommending a restaurant to colleagues in a staff room \\
$\mathrm{J}$ & Giving a presentation in a town hall to promote a political party to the public \\
$\mathrm{K}$ & Recommending interpreters between friends in a pub \\
$\mathrm{L}$ & Discussing how to spend council funds with other local community members in a town hall \\
\hline
\end{tabular}


being non-generalisable. Thus, in attributing more general features to these scenarios (i.e. those found in Table 1) that can be applied to multiple contexts (e.g., whether communication in the situation is 'prepared' or 'unprepared'), it is thereby possible to identify prevalent contextual patterns no matter how specific or unique they are in their description.

For each scenario, two questions were asked. Similar to Stone (2011), the first asked the participant to pick the level of linguistic formality that they would employ in the scenario based upon the description provided. Five responses were presented on a scale: very informal (1), informal (2), neutral (3), formal (4) and very formal (5). Participants could choose any option for each scenario, but were only allowed to choose one per scenario. Furthermore, participants were encouraged to follow their instincts rather than overthink the scenarios, to promote a more realistic representation of how BSL users rapidly adapt their language based upon contextual cues.

The second question of each scenario asked the participants to select the contextual feature that influenced their choice of linguistic formality the most. As aforementioned, each scenario contained an overt indication of topic, people, place and type of communication, hence these four options were made available as responses. A fifth option was also provided, wherein the participant could type an element of context if this was not covered by the other four options. This ensured that participants could give their true opinion and not be restricted by potentially unrepresentative options.

Due to limitations in the capabilities of the survey platform, there was no option to record and send responses in BSL. Not only would this latter method drastically increase the time required to complete the survey, but it would also compromise participant anonymity, as participants would need to film themselves in order to clearly communicate their message in BSL.

Demographic questions were asked in the final section of the survey. This was done to identify current age, estimated age of BSL acquisition, gender, current location, and how the participants acquired BSL. These particular variables were selected to measure specific sociolinguistic influences found in Deaf communities (Bayley et al. 2015), while verifying that the responses came from a range of participants from varied backgrounds. This variation in respondents was desired as Hill (2015) comments upon the wealth of sign language research that uses participants who identify as Deaf from birth or from very young, insisting that this is not representative of the true population of BSL users. Thus, Hill affirms that researchers must

accept that variety of communication and of language experience has become the norm for deaf signers and that sociolinguistic studies of signers whose sign language exposure was delayed are highly encouraged, for the sake of capturing the linguistic and cultural realities (p.203).

A final demographic question asked the participants to clarify if BSL is their primary language of communication. This was used to filter any responses that may have been recorded from those who use BSL as a secondary or non-dominant language (e.g., learners of BSL). The question was posed in this manner instead of asking if the participant is 'Deaf' as this does not suitably delimit the intended population accurately. For example, a participant may identify as 'Deaf' but use a different sign language more frequently than BSL. 


\section{Results}

The responses of 51 participants were recorded in this survey (see Additional File 1 for this data in raw format). Each participant responded to all questions and indicated that BSL was their primary language of communication. Respondents were located in 23 towns and cities across the UK, and were aged between 20 and 60 years old $(M=37.5$, $S D=11.1)$. Ages of BSL acquisition ranged from birth to 23 years old $(M=7.9, S D=$ 5.5). In accordance with categories given by Cormier et al. (2013), 9 participants (18\%) were classed as 'native' signers, 30 (59 \%) as 'early' signers, and 12 (23\%) as 'late' signers. The gender split of respondents was roughly equal, with 27 identifying as female and 24 as male. In terms of their primary method of BSL acquisition, the majority of respondents $(83 \%)$ learned BSL in educational contexts, either at mainstream schools or specialist schools for the Deaf. The remainder (17 \%) learned BSL primarily from within their families.

For each scenario, the arithmetic mean of responses to the first question is calculated in order to find the average linguistic formality score. Table 3 shows the score per scenario, ranked from most informal to most formal. Based upon the responses given, it is possible to estimate population means via confidence intervals. These were calculated at a confidence level of $95 \%$ and are displayed as lower limits (LL) and upper limits (UL).

Table 4 presents the responses for the second question of each scenario, including the factor identified as the most influential when choosing a level of linguistic formality, and the percentage of respondents that selected this feature. 'Type' is classed as the most influential factor for five scenarios, 'People' for four scenarios, and "Place' for three scenarios. 'Topic' does not appear as the most influential factor in any scenarios, and in no instance was 'Other' selected.

When all 612 responses concerning the most influential factor are accumulated and analysed, 216 responses (35\%) class 'People' as the most influential factor when choosing linguistic formality overall, 171 (28 \%) responses select 'Place' and 157 (26\%) responses select 'Type.' Once again, 'Topic' is the least influential factor overall, receiving only 68 selections (11\%). A chi-squared test of independence upon these values demonstrates

Table 3 Ranking scenarios according to mean formality score

\begin{tabular}{|c|c|c|c|c|c|}
\hline \multirow{2}{*}{\multicolumn{2}{|c|}{ Scenario description }} & \multirow[t]{2}{*}{ M } & \multirow[t]{2}{*}{ SD } & \multicolumn{2}{|c|}{$\mathrm{Cl} 95 \%$} \\
\hline & & & & $\overline{\mathrm{LL}}$ & UL \\
\hline J & Recommending interpreters between friends in a pub & 1.78 & 0.73 & 1.58 & 1.99 \\
\hline G & Telling a story to your housemates at home about how you got a pay rise & 1.88 & 1.09 & 1.58 & 2.18 \\
\hline A & Discussing the General Election with friends in a café & 2.18 & 0.79 & 1.95 & 2.40 \\
\hline $\mathrm{H}$ & Recommending a restaurant to colleagues in a staff room & 2.29 & 0.64 & 2.11 & 2.47 \\
\hline $\mathrm{E}$ & Telling your boss in the staff room about a restaurant you like & 2.71 & 0.90 & 2.45 & 2.96 \\
\hline L & Talking to your boss in the pub about your previous experiences when voting & 2.76 & 0.76 & 2.55 & 2.98 \\
\hline C & Ordering food from a waiter in a restaurant & 3.31 & 0.86 & 3.07 & 3.56 \\
\hline $\mathrm{F}$ & Instructing a new colleague at work on how to book an interpreter & 3.59 & 0.78 & 3.37 & 3.81 \\
\hline K & Discussing how to spend council funds with other local community members in a town hall & 3.71 & 0.81 & 3.48 & 3.93 \\
\hline D & Giving a presentation at work to your colleagues about how to book an interpreter & 4.00 & 0.85 & 3.76 & 4.24 \\
\hline । & Giving a presentation in a town hall to promote a political party to the public & 4.43 & 0.78 & 4.21 & 4.65 \\
\hline B & Negotiating a pay rise with your boss in their office & 4.45 & 0.70 & 4.25 & 4.65 \\
\hline
\end{tabular}


Table 4 Most influential aspect of context per scenario

\begin{tabular}{|c|c|c|c|}
\hline & Scenario description & Influence & $\begin{array}{l}\% \text { of overall } \\
\text { response }\end{array}$ \\
\hline A & Discussing the General Election with friends in a café & People & $65 \%$ \\
\hline B & Negotiating a pay rise with your boss in their office & People & $53 \%$ \\
\hline C & Ordering food from a waiter in a restaurant & Type & $55 \%$ \\
\hline D & $\begin{array}{l}\text { Giving a presentation at work to your colleagues about how to book an } \\
\text { interpreter }\end{array}$ & Type & $69 \%$ \\
\hline E & Telling your boss in the staff room about a restaurant you like & Place & $47 \%$ \\
\hline $\mathrm{F}$ & Instructing a new colleague at work on how to book an interpreter & Type & $37 \%$ \\
\hline G & Telling a story to your housemates at home about how you got a pay rise & People & $63 \%$ \\
\hline H & Recommending a restaurant to colleagues in a staff room & Place & $49 \%$ \\
\hline | & $\begin{array}{l}\text { Giving a presentation in a town hall to promote a political party to the } \\
\text { public }\end{array}$ & Type & $63 \%$ \\
\hline J & Recommending interpreters between friends in a pub & People & $43 \%$ \\
\hline K & $\begin{array}{l}\text { Discussing how to spend council funds with other local community } \\
\text { members in a town hall }\end{array}$ & Type & $35 \%$ \\
\hline L & $\begin{array}{l}\text { Talking to your boss in the pub about your previous experiences when } \\
\text { voting }\end{array}$ & Place & $57 \%$ \\
\hline
\end{tabular}

that these results are statistically significant: $\chi^{2}(3, N=612)=75.38, p<0.001$. Figure 1 displays the distribution of selections for most influential factor and formality level for all responses. This visual representation demonstrates the difference in prominence of the four factors, especially with regards to 'Topic.'

Figure 2 displays a stacked accumulation of the selections of formality level per factor, providing an easier method of comparing the proportion of selections overall. It can be seen that, despite its low selection rate, 'Topic' mainly co-occurred with 'Informal,' 'Neutral' and 'Formal' selections, with few choices at either extreme. 'Type' was mostly selected with choices at the formal end of the scale, with the proportion of co-occurrence for 'Formal' and 'Very formal' at close to $75 \%$. In addition, the combination of 'Type' and 'Very informal' did not co-occur in any of the 612 responses. 'Place' tends to co-occur with choices at the informal end of the scale, with selections of 'Very informal' and 'Informal' at over $50 \%$. Finally, 'People' shows the most even distribution of formality level cooccurrence, with a bias towards the informal end of the scale.

Table 5 displays all twelve scenarios, ranked from most informal to most formal, alongside their respective values for interpersonal power distribution, turn-taking structure and the level of preparedness of the interaction. Beginning with power, a one-way

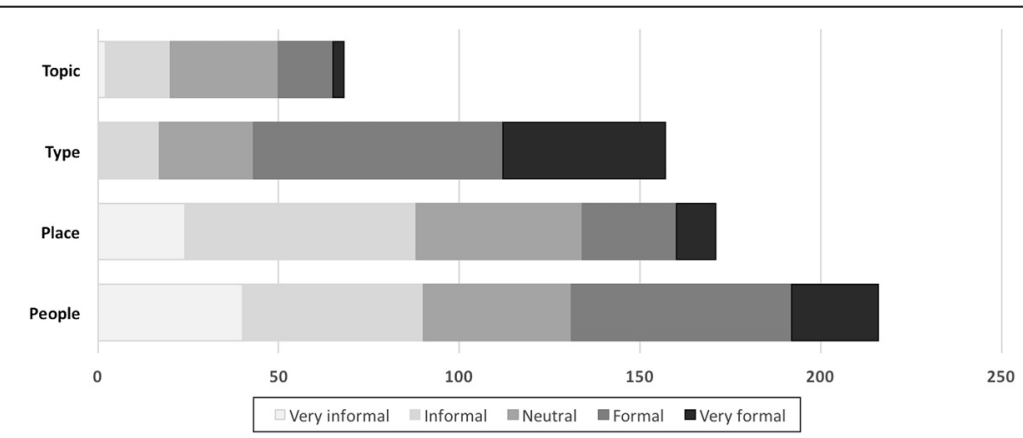

Fig. 1 Total number of individual formality level selections per contextual factor 


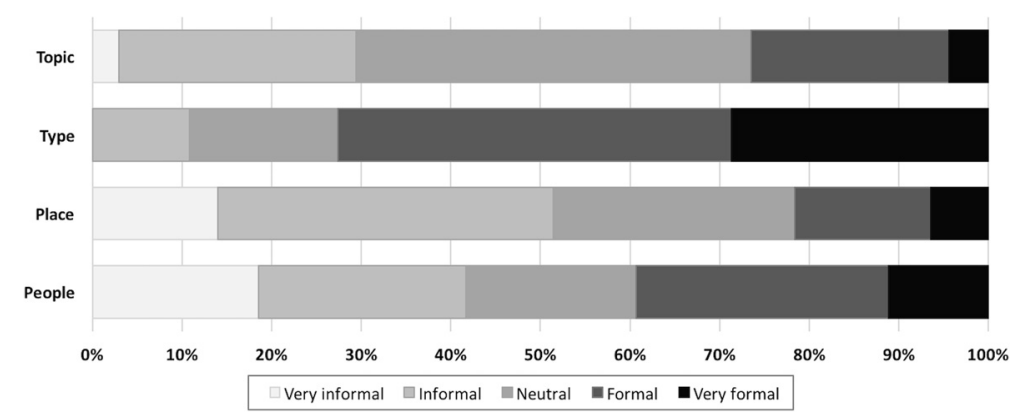

Fig. 2 Cumulative percentage totals of formality level selections per contextual factor

ANOVA produced a statistically significant response, $F(2,12)=9.10, p<0.01$. A posthoc Tukey Honest Significant Difference (HSD) test was applied to compare means with one another, revealing that the difference between 'balance' and 'imbalance' is significant $(p<0.05)$, as is the difference between 'balance' and 'mid' $(p<0.05)$. However, 'mid' and 'imbalance' show almost no difference at all $(p=0.90)$

As the features of turn and preparedness select from only two values, independent $\mathrm{t}$-tests were applied to each. For turn, dialogic interactions $(M=2.79, S D=0.89)$ tended to occur with less formal language than monologic interactions $(M=4.01, S D=$ $0.42), t(12)=2.24, p=0.05$. For preparedness, interactions that involve no explicit preparation before the communication $(M=2.47, S D=0.66)$ tend to employ less formal language than those that are explicitly prepared $(M=3.96, S D=0.26), t(12)=4.19, p<0.01$.

\section{Discussion and further study}

A number of observations can be made from these results, starting with the formality scores attributed to each scenario and their confidence intervals. At a confidence level of $95 \%$, the responses given in this study do not deviate \pm 0.3 points from the calculated means. This range, coupled with low standard deviations, suggests that the population of Deaf BSL users may employ the same level of linguistic formality if they found themselves

Table 5 Power, turn, and preparedness post-hoc values for each scenario

\begin{tabular}{llll}
\hline Scenario description & Power & Turn & Preparedness \\
\hline J Recommending interpreters between friends in a pub & Balance & Dia & Spontaneous \\
G Telling a story to your housemates at home about how you got a pay rise & Balance & Dia & Spontaneous \\
A Discussing the General Election with friends in a café & Balance & Dia & Spontaneous \\
H Recommending a restaurant to colleagues in a staff room & Balance & Dia & Spontaneous \\
E Telling your boss in the staff room about a restaurant you like & Imbalance & Dia & Spontaneous \\
L Talking to your boss in the pub about your previous experiences when voting & Imbalance & Dia & Spontaneous \\
C Ordering food from a waiter in a restaurant & Mid & Dia & Prepared \\
F Instructing a new colleague at work on how to book an interpreter & Mid & Mono Prepared \\
K Discussing how to spend council funds with other local community & Mid & Dia & Spontaneous \\
members in a town hall & Mid & Mono Prepared \\
D Giving a presentation at work to your colleagues about how to book & Im interpreter & Imbalance & Mono Prepared \\
I Giving a presentation in a town hall to promote a political party to & & \\
the public & Imbalance & Dia & Prepared \\
B Negotiating a pay rise with your boss in their office & &
\end{tabular}


in the scenarios described. ${ }^{3}$ From the demographic data, the responses originated from a range of participants in terms of current age, age of BSL acquisition, gender and location. Thus, the agreement between a variety of BSL users spread across the UK seems to be of a high level, suggesting little to no regional influence on considerations of formality. This follows the theory of expectancy in formality, proposed by Arndt and Janney (1987), who state that stable communication occurs when there is a match between the expected formality level of the situation and that chosen by the communicators. Any discrepancy would require "immediate negotiation" (p.186) before the communication would be able to continue in a stable manner, yet from what is calculated, there is no indication that such an event would likely arise regularly.

The scenarios, when ordered from most informal to most formal (see Table 3), display common contextual themes towards both poles of a formality continuum. Many of these are closely related to the features observed within the category of tenor which, as aforementioned by Berry (2013), is the category of context over which the participants have the most control. Post-hoc values were applied to each scenario in accordance with the various measured contextual features (see Table 1). For instance, 'friends' appears in many of the scenarios judged to use informal communication, alongside locations such as 'staff room' and 'pub.' More formal scores, however, correlate with themes such as 'presentation' and 'boss.' When considering the contextual feature of role, those situations that scored closer to the informal pole $(M<3.00)$ tend to involve roles with stereotypically close interpersonal relationships, such as friends and colleagues, whereas scenarios at the formal pole $(M>3.00)$ involve social strangers. From this, the feature of familiarity between interlocutors can be derived, as those who are socially proximal to one another will have an assumed higher level of familiarity than those who are socially distal (i.e. strangers). Therefore, high familiarity relationships tend to invoke more informal language, whereas low familiarity relationships are likely to call upon more formal language.

The feature of power for each scenario is based on the values attributed to role and familiarity, accompanied by the balance of power that would generally be expected in such scenarios. A post-hoc Tukey HSD test revealed that significant differences were found between the formality scores for 'balanced' and 'imbalanced' interactions, suggesting that informal language would likely be used in situations where power between language users is balanced. Additionally, a non-significant difference was discovered between scenarios where a power imbalance is perceived and scenarios wherein power falls somewhere between 'balanced' and 'imbalanced' (hence 'mid' being designated to scenarios $\mathrm{C}, \mathrm{D}, \mathrm{F}$ and $\mathrm{K}$ ). In summary, unless a perceived balance of power between interlocutors exists, more formal language will tend to be used. Such an effect has been noted as a politeness strategy in languages with spoken and written modes of communication including English and Korean, alongside other sign languages (English: Arndt and Janney 1987; Korean: Strauss and Eun 2005; Japanese Sign Language/Nihon Shuwa: George 2011).

When considering turn, dialogically and monologically structured scenarios show some differences in terms of the linguistic formality employed. However, the calculated $\mathrm{p}$-value of the independent t-test is equal to 0.05 , rather than below it. This suggests that turn-taking structures have a marginal influence on linguistic formality. As is shown in Table 5, dialogic interactions are interspersed, with both the most informal 
scenario (J) and the most formal scenario (B) classed as dialogic, despite dialogic interactions being weighted overall towards the informal end of the spectrum. This may also indicate that the use of 'dialogic' and 'monologic' may need revision as, for instance, 'dialogic interactions with interruption/overlap' and 'dialogic interactions without interruption/overlap.'

For the feature of preparedness, the difference between 'prepared' and 'unprepared' language in scenarios is more marked. Scenarios in which language is not explicitly prepared beforehand resulted in a lower linguistic formality score than scenarios with prepared language. This falls in line with what is observed by Broderick (1978) who finds that prepared communication prior to interaction presents more formal linguistic features that that which is unprepared. Only scenario $\mathrm{K}$ falls outside of this pattern in attaining a score leaning towards the more formal end of the spectrum $(M=3.71)$. This anomaly may be explained because the 'Type' of communication in this scenario ('Discussing how to spend council funds with other local community members in a town hall') is identified as the most influential factor. As Fig. 2 reveals, 'Type' co-occurs with 'Formal' or 'Very formal' selections for $73 \%$ of the overall responses. As such, although a pattern seems to appear with regards to formality and preparedness, other features may have a more overriding influence.

Concerning the features of field, namely socio-semiotic activity and topic, there are no clear or significant patterns found. In addition, 'Topic' was selected the least amount of times as most influential factor. This would infer that the field component of context has a weak overall influence on the level of linguistic formality chosen by BSL users. Examples of this can be drawn from the data: scenarios D, F and J all concern the topic of 'interpreters' or 'interpreting,' yet the calculated mean scores for formality are 4.00, 3.59 and 1.78 respectively, ranging from the minimum mean value to one of the highest mean values. A less marked but similar effect is found in scenarios A, I and L, each of which concern the topic of 'politics', yet the mean formality scores are calculated as $2.18,4.43$ and 2.76. This variation supports the notion that the topic alone is not the strongest feature in influencing formality, and instead, it is in combination with other contextual features that variation occurs. This finding seems to counteract the positions proposed by Giles and Coupland (1991), who state that "the subject matter of the activity type itself has important speech correlates" (p.8), and of Labov (2001) who, in his research identifying 'casual' and 'careful' speech in linguistic interviews, states that the topic of conversation can have an effect upon the style that language users employ (i.e. more or less formal). This may be explained by the authors' classifications of topic including an emotional aspect with regards to how those in communication value the topic, thus causing a change in style, whereas topic from Halliday and Matthiessen's (2013) perspective refers principally to the subject matter at hand. This emotional aspect, however, can be paralleled to Halliday and Matthiessen's feature of valuation (i.e. how those in communication imbue the topic, either positively or negatively). Intriguingly, Halliday and Matthiessen class valuation as a feature of tenor rather than one of field, and although this study did not look into this feature, this categorisation seems to reinforce the idea that the tenor of the situation has the strongest influence on perceived contextual formality and employed linguistic formality.

Finally, no significant patterns were found between responses when comparing current age, age of acquisition, location, and method of BSL acquisition. One interpretation could 
suggest that these features do not have a strong bearing on linguistic formality. However, given the range of values that the demographic data could possess, it is more likely that the sample size was not representative (e.g. 51 participants spread over 23 locations averages at 2.2 responses per location). Thus, a larger sample size may produce more noticeable patterns. While the recorded gender binary shows no significant difference overall, it is noted that the largest difference between the means of male and female responses is found in scenario C: men $(M=3.00, S D=0.82)$ chose a more neutral formality level than women $(M=3.59, S D=0.78)$ when presented with the scenario of ordering food from a waiter. With this difference between means totalling 0.59 , whereas the differences between means according participant gender for other scenarios range from 0.01 to 0.37 , this may imply a more marked split in linguistic formality in 'service interactions.' However, the data obtained here are not robust enough to be generalised in this manner, and would need further research to back up this claim.

Overall, the results obtained in this paper suggest that when given a brief overview of a communicative scenario, users of BSL will more than likely select similar levels of linguistic formality with which to communicate. This choice of formality does not fall into a simple formal-informal dichotomy, and there are trends in the contextual configurations of those situations that can be classed as 'more formal' or 'more informal.' In analysing elements of context in greater detail, there is a propensity for the interpersonal factors between communicators to be the main influence when choosing a linguistic formality level. This aligns with Labov's (2001) indication that "shifts in the audience (are) sometimes the primary means of controlling style-shifting" (p.88), and Berry's (2013) identification of the control that language users may exercise over interpersonal contextual factors.

Of course, this does not dismiss other aspects of context and their role in formality. In instances where informal language is used, the people involved in the interaction are usually well-known to the signer, such as friends, acquaintances or colleagues, whereas formal language is used between those where there is a greater social distance. The location in which the interaction takes place is also influential, particularly where informal language is likely to be found (e.g. pub, café, at home), relating to Leckie-Tarry's (1995) feature of institutionalisation. Nevertheless, the topic of the interaction does not present any significant influence, suggesting that the subject matter of an interaction has little impact upon the formality employed by BSL users, contrary to Labov (2001).

This study begins to fill gaps in current understanding of BSL from the systemic functional perspective. There are few studies on languages in the visual-spatial modality that use SFL as an analytical framework, and this study provides a theoretical launch pad with which to tap into how sign languages function depending on communicative context. Nonetheless, it must be remembered that this study is exploratory in its nature. While there are results that appear significant, both matching and contesting what has been found in spoken language research, further validation is necessary in order to support these findings. This could be achieved in numerous ways, from direct replication to adaptation with another sign language. The present study may also be expanded to assess various additional contextual elements identified in SFL, such as changes in communication channel (e.g. face-to-face vs. online). An extended investigation may observe other features of context identified by Halliday and Matthiessen (2013), Eggins (2004) and Leckie-Tarry (1995), or may move into more complex realms 
and look at the paradigmatic relationships of contextual configurations as espoused by researchers such as Butt and Wegener (2008), Bowcher (2013, 2014), and Hasan (2014). In taking what has been found in this analysis, future studies will observe how language manifests itself in differing contexts, aiming to identify patterns of variation at the lexicogrammatical level between 'formal' and 'informal' contexts.

Methodological alterations, aside from those mentioned in the discussion, also require consideration. Firstly, rather than using short descriptions of scenarios, it may be possible to use videos depicting different scenarios in which communication is taking place. These may be accompanied by scenario descriptions, thereby coalescing contextual and linguistic aspects. Secondly, the post-hoc attribution of values to features such as power and preparedness was performed in a subjective manner due to the small amount of information provided in the scenario descriptions. The results of this study appear significant, and there is acceptance that "there is often much homogeneity of episodic representations (of context, thereby explaining) why objective situational definitions have had some success in predicting linguistic variation" (Giles and Coupland 1991, p.15). However, this could be investigated further by increasing the level of detail given in each description. Caution will need to be taken in this latter instance, though, to ensure that the scenarios do not become too specific, resulting in data that may be challenging to generalise to a wider population. Finally, it would be pertinent to ensure that all participants understand the notion of 'formality' in the same way. As the distribution of the survey for this study was online, there were definitions and examples of the terms 'formal' and 'informal' provided in BSL prior to responding to the questions. However, if it were possible to replicate this study with participants meeting the author face-to-face prior to commencing the survey, it would open up the opportunity to ensure a more level understanding of 'formality' between participants, alongside the chance for any further clarification of the study.

\section{Endnotes}

1a An uppercase ' $\mathrm{D}$ ' is used when referring to Deaf communities to represent those who identify as members of the community, and who use a sign language as their primary mode of communication.

2b While recent volumes have researched aspects of BSL alongside other sign languages (e.g. Pfau et al. 2012), the work of Sutton-Spence and Woll (1999) focusses purely on the construction of BSL.

${ }^{3 c}$ It must be stressed that the results of this study are yet to be based on linguistic data, but future studies will investigate the lexicogrammatical manifestations of 'formal' and 'informal' BSL using systemic functional methods. The results of this study, therefore, may be interpreted as further hypotheses to be supported or refuted via the analysis of linguistic data.

\section{Additional file}

Additional file 1: Raw data obtained from the online formality survey. (XLSX $138 \mathrm{~kb}$ ) 


\section{Competing interests}

The author declares that there are no competing interests, financial or non-financial, in the publication of this work.

Authors' contributions

All work was completed by LAR.

\section{Authors' information}

LAR is a doctoral student and associate lecturer in linguistics at the Bristol Centre for Linguistics, University of the West of England. His current doctoral research focusses on the use of British Sign Language in different communicative environments and identifying lexicogrammatical patterns of variation. His research interests include sociolinguistics, sign languages, the use of technology in communication and systemic functional approaches to linguistic analysis.

\section{Acknowledgements}

The author would like to thank the anonymous members of the British Deaf community who took part in the online survey, thus providing the data to complete the research. Thanks is given to David Ellington, who assisted with filming the BSL interpretations of the scenarios, and the authors' research supervisors, Dr Jeanette Sakel and Dr Anna Piasecki, for their guidance with data and article structure. In addition, the author thanks the reviewers of the original draft of this paper who provided not only feedback for a more coherent structure, but many additional avenues of research and theory that can be explored in the future.

\section{Received: 30 September 2015 Accepted: 17 December 2015}

\section{Published online: 23 December 2015}

\section{References}

Arik, Engin. 2014. Sign language research in web of science. Journal of Scientometric Research 3: 143-149. doi:10.4103/ 2320-0057.153583.

Arndt, Horst, and Richard W. Janney. 1987. InterGrammar: Toward an integrative model of verbal, prosodic and kinesic choices in speech. Berlin: Mouton de Gruyter.

Bayley, Robert, Adam C. Schembri, and Ceil Lucas. 2015. Variation and change in sign languages. In Sociolinguistics and Deaf Communities, ed. Adam C. Schembri and Ceil Lucas, 61-94. Cambridge: Cambridge University Press.

Berger, Charles R., and James J. Bradac. 1982. Language and Social Knowledge: Uncertainty in Interpersonal Relations. London: Edward Arnold.

Berry, Mary. 2013. Towards a description of the differences between formal written English and informal spoken English. In Systemic Functional Linguistics: Exploring Choice, ed. Lise Fontaine, Tom Bartlett, and Gerard O'Grady, 365-383. Cambridge: Cambridge University Press.

Biber, D. 1995. Dimensions of Register Variation: A Cross-Linquistic Comparison. Cambridge: Cambridge University Press.

Bowcher, Wendy. 2013. Material action as choice in field. In Systemic Functional Linguistics: Exploring Choice, ed. Lise Fontaine, Tom Bartlett, and Gerard O'Grady, 318-341. Cambridge: Cambridge University Press.

Bowcher, Wendy. 2014. Issues in developing unified systems for contextual Field and Mode. Functions of language 21 : 176-209. doi:10.1075/fol.21.2.02bow.

Broderick, John. 1978. Casual, Careful, and Formal Styles of English: An Empirical Study. South Atlantic American Dialect Society Conferences Proceeding. Old Dominion University. http://ww2.odu.edu/al/jpbroder/jpb_joos_research_1978. pdf. Accessed 14 September 2015.

Butler, Christopher S. 2003. Structure and Function: A Guide to Three Major Structural-Functional Theories, vol. II. Amsterdam: John Benjamins.

Butt, David, and Rebekah Wegener. 2008. The Work of concepts: context and metafunction in the systemic functional model. In Continuing discourse on language: a functional perspective. Vol. II, ed. Ruqaiya Hasan, Christian Matthiessen, and Jonathan Webster, 589-618. London: Equinox.

Caffarel, Alice. 2006. A Systemic Functional Grammar of French. London: Continuum.

Cormier, Kearsy, Sandra Smith, and Martine Zwets. 2013. Framing constructed action in British Sign Language narratives. Journal of Pragmatics 55: 119-139. doi:10.1016/j.pragma.2013.06.002.

Deuchar, Margaret. 1978. Diglossia in British Sign Language. Working Papers in Sociolinguistics 46: 1-49.

Deuchar, Margaret. 1984. British Sign Language. London: Routeledge.

Eckhert, Penelope, and John R. Rickford. 2001. Style and Sociolinquistic Variation. Cambridge: Cambridge University Press.

Eggins, Suzanne. 2004. An Introduction to Systemic Functional Linguistics, 2nd ed. London: Continuum.

Ferguson, Charles A. 1959. Diglossia. Word 15: 325-40.

George, J.E. 2011. Politeness in Japanese Sign Language (JSL): Polite JSL expression as evidence for intermodal language contact influence. PhD thesis. Berkeley: University of California.

Giles, Howard, and Nikolas Coupland. 1991. Language: Contexts and Consequences. Buckingham: Open University Press. Halliday, Michael A.K. 1978. Language as Social Semiotic. London: Edward Arnold.

Halliday, Michael A.K., and Ruqaiya Hasan. 1989. Language, context and text: aspects of language in a social-semiotic perspective, 2nd ed. Oxford: Oxford University Press.

Halliday, Michael A.K., and Christian M.I.M. Matthiessen. 2013. Halliday's introduction to functional grammar, 4th ed. Oxford: Routeledge.

Halliday, Michael A.K., and Johnathan J. Webster. 2009. Continuum Companion to Systemic Functional Linguistics. London: Continuum.

Hasan, Ruqaiya. 1993. Contexts for meaning. In Georgetown University Round Table on Languages and Linguistics (GURT) 1992, ed. James E. Alatis, 79-103. Georgetown: Georgetown University Press.

Hasan, Ruqaiya. 1999. Speaking with reference to context. In Text and Context in Functional Linguistics, ed. Mohsen Ghadessy, 219-328. Amsterdam: John Benjamins. 
Hasan, Ruqaiya. 2014. Towards a paradigmatic description of context: systems, metafunctions, and semantics. Functional Linguistics 2: 1-54. doi:10.1186/s40554-014-0009-y.

Heylighen, Francis, and Jean-Marc Dewaele. 2002. Variation in the Contextuality of Language: An Empirical Measure. Foundations of Science 7: 293-340. doi:10.1023/A:1019661126744.

Hill, Joseph. 2015. Data collection in sociolinguistics. In Research Methods in Sign Language Studies: A Practical Guide, ed. Eleni Orfanidou, Bencie Woll, and Gary Morgan, 193-205. Oxford: Wiley Blackwell.

Johnston, Trevor. 1996. Function and medium in the forms of linguistic expression found in a sign language. International Review of Sign Linguistics 1: 57-94.

Joos, Martin. 1961. The Five Clocks: A linguistic excursion into the five styles of English usage. New York: Harcourt, Brace and World. Labov, William. 1972. Sociolingusitic Patterns. Philadelphia: University of Pennsylvania Press.

Labov, William. 1984. Field Methods of the Project on Linguistic Change and Variation. In Language in Use, ed. John Baugh and Joel Sherzer, 28-53. Englewood Cliffs: Prentice Hall.

Labov, William. 2001. The anatomy of style-shifting. In Style and Sociolinguistic Variation, ed. Penelope Eckert and John R. Rickford, 85-108. Cambridge: Cambridge University Press.

Lavid, Julia, Jorge Arús, and Juan R. Zamorano-Mansilla. 2010. Systemic Functional Grammar of Spanish: A Contrastive Study with English, vol. 1. London: Continuum.

Leckie-Tarry, Helen. 1995. Lanquage \& Context: A Functional Linquistic Theory of Register. London: Pinter.

Lee, Dorothy M. 1982. Are There Really Signs of Diglossia?: Re-Examining the Situation. Sign Language Studies 35: 127-52. doi:10.1353/sls.1982.0002.

Lemke, Jay L. 1988. Text Structure and Text Semantics. In Pragmatics, Discourse and Text: Some Systemically Inspired Approaches, ed. Erich H. Steiner and Robert Veltman, 158-170. Norwood: Alex.

Levin, Harry, and Peter Garrett. 1990. Sentence structure and formality. Language in society 19: 511-520.

Li, Haiying, Zhiqiang Cai, and Arthur C. Graesser. 2013. Comparing Two Measures for Formality. Twenty-Sixth International Florida Artificial Intelligence Research Society Conference Proceedings: 220-225.

Lukin, Annabelle, Alison Moore, Maria Herke, Rebekah Wegener, and Wu. Canzhong. 2011. Halliday's model of register revisited and explored. Linquistics and the Human Sciences 4: 187-213.

Malinowski, Bronislaw. 1923. The problem of meaning in primitive languages. In The Meaning of Meaning, ed. C.K. Ogden and I.A. Richards, 297-336. London: Kegan Paul.

Martin, James R. 2014. Evolving systemic functional linguistics: beyond the clause. Functional Linguistics 1: 1-24. doi:10. 1186/2196-419X-1-3.

Matthiessen, Christian M.I.M., Kazuhiro Teruya, and Marvin Lam. 2010. Key Terms in Systemic Functional Linguistics. London: Continuum.

Metzger, Melanie. 1993. Pronoun variation in formal and informal discourse. In Communication Forum 1993, ed. Elizabeth A. Winston, 132-149. Washington, DC: Gallaudet University Press.

Napier, Jemina. 2003. A Sociolinguistic Analysis of the Occurrence and Types of Omissions Produced by Australian Sign Language-English Interpreters. In From Topic Boundaries to Omission: New Research on Interpretation, ed. Melanie Metzger, Steven Collins, Valerie Dively, and Risa Shaw, 99-153. Washington, DC: Gallaudet University Press.

Pfau, Roland, Markus Steinbach, and Bencie Woll. 2012. Sign Language: An international handbook. Berlin: De Gruyter Mouton.

Quinto-Pozos, David, and Wanette Reynolds. 2012. ASL Discourse Strategies: Chaining and Connecting-Explaining across Audiences. Sign Language Studies 12: 211-235. doi:10.1353/sls.2011.0021.

Rooy, Van, Lize Terblanche Bertus, Christoph Haase, and Joseph Schmied. 2010. Register differentiation in East African English: A multidimensional study. English World-Wide 31: 311-349. doi:10.1075/eww.31.3.04van.

Stamp, Rose, Adam C. Schembri, Jordan Fenlon, and Ramas Rentelis. 2015. Sociolinguistic variation and change of British Sign Language number signs. Sign Language Studies 15: 151-181. doi:10.1353/sls.2015.0001.

Stone, Chris. 2011. Register, Discourse and Genre in British Sign Language (BSL). In Discourse in signed languages, ed. Cynthia Roy, 121-154. Washington: Gallaudet University Press.

Strauss, Susan, and Jong Oh. Eun. 2005. Indexicality and honorific speech level choice in Korean. Linguistics 43: 611-651. doi:10.1515/ling.2005.43.3.611.

Sutton-Spence, Rachel, and Bencie Woll. 1999. The Linguistics of British Sign Language: An introduction. Cambridge: Cambridge University Press.

Van Dijk, Teun A. 2008. Discourse and Context - A sociocognitive approach. Cambridge: Cambridge University Press.

Wish, Myron, and Susan J. Kaplan. 1977. Toward an Implicit Theory of Interpersonal Communication. American Sociological Association 40: 234-246. doi:10.2307/3033530.

Zimmer, June. 1989. Register Variation in American Sign Language. In The Sociolinguistics of the Deaf Community, ed. Ceil Lucas, 253-272. San Diego: Academic. 